\title{
Léonard Burnand, Les pamphlets contre Necker. Médias et imaginaire politique au XVIII ${ }^{\mathrm{e}}$ siècle
}

Annie Duprat

\section{Q OpenEdition \\ 12 Journals}

Édition électronique

URL : https://journals.openedition.org/ahrf/11742

DOI : $10.4000 /$ ahrf. 11742

ISSN : 1952-403X

Éditeur :

Armand Colin, Société des études robespierristes

Édition imprimée

Date de publication : 1 septembre 2010

Pagination : 206-208

ISBN : 978-2-200-92633-5

ISSN : 0003-4436

Référence électronique

Annie Duprat, «Léonard Burnand, Les pamphlets contre Necker. Médias et imaginaire politique au xVIII siècle ", Annales historiques de la Révolution française [En ligne], 361 | juillet-septembre 2010, mis en ligne le 22 mars 2011, consulté le 23 avril 2022. URL : http://journals.openedition.org/ahrf/11742 ; DOl : https://doi.org/10.4000/ahrf.11742

Ce document a été généré automatiquement le 23 avril 2022.

Tous droits réservés 


\title{
Léonard Burnand, Les pamphlets contre Necker. Médias et imaginaire politique au XVIII ${ }^{\mathrm{e}}$ siècle
}

\author{
Annie Duprat
}

\section{RÉFÉRENCE}

Léonard Burnand, Les pamphlets contre Necker. Médias et imaginaire politique au XVIII ${ }^{\mathrm{e}}$ siècle, Paris, Classiques Garnier, 2009, 410 p., ISBN 978-2-8124-0066-7, $59 €$

1 Le Genevois Jacques Necker, banquier protestant, a été la cheville ouvrière des multiples tentatives de réformes, et d'assainissement, du système fisco-financier de la vieille monarchie française. Étranger, pas catholique du tout - il avait épousé une fille de pasteur - il est également banquier, un état assez déconsidéré après les innovations malheureuses de Law quelques décennies plus tôt. Necker a assisté, à son corps défendant, à la déroute de la monarchie avant de prendre le chemin du retour en Suisse en 1790. Nommé en 1777 "directeur général des finances", et non "contrôleur général » en raison de sa religion, il commence par accompagner ses réformes d'une intense production de textes justificatifs. Il se sert également des réseaux établis par son épouse grâce à son salon. Mais il se heurte bien vite à la défiance, puis à la franche hostilité des physiocrates. Les deux camps qui vont s'affronter durant plus de vingt ans sont très tranchés car, outre des querelles de personnes (face à Necker, il y a Turgot, Condorcet et Voltaire, par exemple, ce dernier tentant de se rapprocher de Necker dès que ce dernier accède au pouvoir, après 1775 , comme le note Léonard Burnand, p. 66) on assiste à l'affrontement de deux conceptions du développement économique de la France. Grossièrement, du côté des "sullistes ", comme ils se nomment eux-mêmes, on trouve, les physiocrates déjà évoqués, partisans d'une richesse fondée sur la propriété foncière et la mise en valeur terrienne; Necker, en revanche, se place du côté des " colbertistes ", qui encouragent autant les initiatives privées que le rôle des autorités 
centrales dans le développement d'une économie de la marchandise et de la manufacture. Dès que le banquier genevois publie un Éloge de Jean-Baptiste Colbert, en 1773, puis Sur la législation et le commerce des grains, en 1775, Condorcet réplique par Sur l'abolition des corvées, 1775, et Réflexions sur le commerce des blés, en 1776, tandis que l'abbé Nicolas Baudeau, polémiste habile et bien informé, fait paraître Éclaircissements demandés à $M . N^{* *}$ sur ses principes économiques et sur ses projets de législation au nom des propriétaires fonciers et des cultivateurs français. L'ouvrage, vif dans la forme et le sérieux et argumenté sur le fond, remporte un succès important dont témoignent les commentaires dans nombre de ces textes dont le projet est de « dévoiler» au public la réalité des enjeux politiques du moment. Les Mémoires secrets, de Pidansat de Mairobert, La correspondance littéraire secrète de Métra et L'année littéraire de Fréron en témoignent. Necker, qui se tenait au courant de tous les écrits sur son action, a lu et minutieusement annoté son exemplaire du texte de Nicolas Baudeau. Léonard Burnand a retrouvé ce texte manuscrit à la Bibliothèque de Genève. Les commentaires du Genevois (plusieurs exemples sont donnés p. 51-53) témoignent de son irritation à voir ses propos déformés et même contrefaits; ses réactions prouvent qu'il prenait très au sérieux toutes les critiques qui lui étaient opposées: ici s'exprime une différence majeure avec les diffamations ordinaires dont le xviII ${ }^{\mathrm{e}}$ siècle était friand car la cible, en l'occurrence un banquier et économiste de pouvoir, a pris les choses très au sérieux et n'a cessé de ferrailler contre ses adversaires. Tel n'a pas été le cas de la reine et de son entourage proche, par exemple, qui ont traité des attaques bien plus insidieuses encore par l'ironie ou le dédain. Le caractère profond de Necker, sûr de ses positions et très irrité par les procédés du pamphlétaire qu'il considère comme un calomniateur, se dévoile dans ses notes manuscrites : «où ai-je rien dit de pareil ?", p. 47, «toute cette partie est de pure invention du critique ", p. 8. Il est aussi volontiers condescendant: "si vous ne pouvez suivre que les vérités les plus simples, ce n'est pas ma faute », p. 38. Parfois, lorsqu'il considère qu'il faut argumenter davantage, il développe ses choix économiques en regard de ceux de l'abbé Baudeau (voir le livre de L. Burnand, p. 53). Mais il n'a pas souhaité diffuser ces commentaires pour l'instruction du public. Le texte de Nicolas Baudeau est comme le coup d'envoi d'une longue querelle par voie de libelles et de presse.

2 Léonard Burnand organise son livre en six chapitres chronologiques montrant bien comment la propagande (celle qui est venue de Necker pour justifier son action) génère la critique et nourrit les polémiques. Le premier chapitre est consacré à la guerre des farines et à ses conséquences. Bien après Steven Kaplan (Le complot de famine: histoire d'une rumeur au XVIII' siècle, trad. française 1983), et à l'aide d'autres sources, souvent inédites, Léonard Burnand nous place au cœur de la crise agraire pré-révolutionnaire et des solutions proposées qui ont engendré tant de peurs et de débats. L'abbé Morellet, pourtant habitué du salon de madame Necker, devient le bras armé de Turgot dont il prend la défense à peine le texte de Necker, De la législation du commerce des grains paru. C'est donc en juin 1775, en même temps que l'ouvrage de Baudeau, que paraît Analyse de l'ouvrage intitulé "De la législation du commerce des grains». Prêt à mordre tous ceux qui attaquent la main qui le nourrit, l'abbé Morellet devient « l'abbé Mords-les », comme l'a écrit joliment Voltaire... Les oppositions aux théories de Necker sont légion : même la chanson se mêle de la polémique, avec un grand succès (voir p. 72). Le second chapitre est consacré aux années 1780, acmé de la cabale anti-neckerienne suscitée en particulier par la publication du Compte-rendu au Roi sur les finances de la France en janvier 1781. Son principal adversaire est à présent Jacques-Mathieu Augeard, dont le 
rôle politique est bien plus important que la postérité n'en a gardé le souvenir. Homme de l'ombre, homme de réseaux, Augeard a rédigé des Mémoires secrets d'une très grande importance, publiés en 1866 de façon posthume. Entre Augeard et Necker, l'attaque fut frontale et sans merci, puisqu'elle passe par la case procès, par la case destruction des presses d'imprimerie et par la case prison... Augeard, qui jouit de la protection de membres de la cour comme le comte d'Artois, attaque Necker en raison de ses origines étrangères, de sa confession protestante mais aussi de ses choix économiques - sur la question de l'emprunt en particulier - et sur tous ses écrits. Léonard Burnand, avec une grande vivacité de style, nous fait vivre les scansions plus ou moins rocambolesques de ce qui s'apparente à une véritable guerre sur la conduite économique d'un pays : madame Necker, travestie en homme, parcourt les librairies pour se saisir des libelles hostiles à son mari (on notera la confirmation de l'attribution à Isaac Panchaud d'une Lettre à $M$. Necker, directeur général des finances, réputée avoir été publiée à Liège, donc surnommée La Liégeoise) et va même jusqu'à faire arrêter des libraires... Les feux ne s'éteignent pas dans les années suivantes et Necker, bien que soutenu par Maurepas, se considère comme un « héros assiégé » (1784-1789), en particulier juste à l'occasion de la réunion de l'Assemblée des notables, qui sacre pourtant son triomphe en 1789 (chapitre 4). Mais, après Condorcet et Baudeau, après Voltaire, Morellet, Calonne, Augeard et beaucoup d'autres, Necker va trouver en la personne de Marat un ennemi dont la plume, beaucoup plus acérée, est également encore plus vindicative, car il se présente en défenseur du peuple face aux oppresseurs du gouvernement et de la cour... Le chapitre 5, ingénieusement titré "L'idole brisée ", montre les contradictions des prises de position de Necker, entre le responsable des finances de la France avant les États généraux qui avait œuvré en faveur du doublement du Tiers, et celui qui, en 1790, se prononçait contre l'abolition des titres de noblesse... Contradiction insupportable aux yeux de Marat comme à ceux de Jean-Jacques Rutlidge, dramaturge d'origine irlandaise. Ce dernier revient sur l'approvisionnement en blés de la capitale française ; arrêté en novembre 1789 sous l'accusation de colporter des fausses rumeurs destinées à effrayer le peuple, il n'est libéré qu'en janvier 1790. Ce point est important car on sait que le vote de la loi martiale a suivi de quelques heures l'affaire de l'assassinat à Paris du boulanger François le 21 octobre 1789: l'arrière-plan volontiers dramatisé par les querelles politiciennes n'a sans doute jamais été assez étudié pour mieux comprendre les raisons de l'Assemblée constituante. "Le géant [était] devenu pygmée », en 1790 : il essuie encore de nombreuses attaques, auxquelles il ne cesse de répondre, avant de fuir en 1790 vers Coppet.

3 À la fin de cette étude très informée (la plupart des textes analysés avaient été à peine évoqués dans les différentes études sur l'opinion publique) et parfaitement maîtrisée, car l'auteur sait mettre en relation les événements avec les " médias », pour reprendre le sous-titre de son livre (libelles anonymes, pamphlets signés, presse périodique et estampes) pour en tirer des conclusions originales. En effet, il faut bien reconnaître que, travailler sur l'opinion publique et tout particulièrement sur la rumeur, après Jean Égret et Robert Darnton, pour ne citer que les historiens les plus fameux, présente un certain nombre de risques que Léonard Burnand sait parfaitement éviter : ne mettre en exergue dans ces textes que des récits portant sur le cercle familial de Necker et de son épouse ou encore utiliser ces sources dans une perspective étroitement téléologique. Bien au contraire, il nous conduit à réfléchir aux choix économiques ouverts dans les années 1770-1790 et à voir comment toutes les tentatives de réforme du royaume ont été conduites à l'échec. 
4 Dans l'ultime chapitre de son livre, sobrement intitulé «La postérité des pamphlets anti-neckériens. Mode de perpétuation d'une légende noire», Léonard Burnand démontre comment l'historiographie de Jacques Necker s'est forgée, en prenant ce qui était écrit dans les pamphlets hostiles au ministre comme des éléments de la vérité établissant ainsi, de facto, une image noire du Genevois. Sa démonstration est très convaincante lorsqu'il examine le livre de Françoise Chandernagor, et le film télévisé, L'enfant des Lumières, dont la documentation historique se fonde essentiellement sur La Liégeoise d'Isaac Panchaud! Mieux encore, il fait revivre la frayeur qui a saisi Genève en 1962 avant la représentation d'une pièce de théâtre, Un banquier sans visage, écrite par Walter Weideli, jeune dramaturge réputé de gauche mais qui avait utilisé l'ouvrage canonique d'Herbert Lüthy, La banque protestante en France, de la révocation de l'Édit de Nantes à la Révolution, 1959-1961, lequel s'était inspiré des textes anti-neckériens... Partant d'analyses détaillées et d'informations à peu près oubliées aujourd'hui, Léonard Burnand parvient à la conclusion que l'on ne peut plus écrire sur Necker, tant la légende noire a submergé la vérité des faits. Nous avions formulé une conclusion du même type à propos de Marie-Antoinette. 